\title{
Introduction
}

\section{Metabolic-Cognitive Syndrome: Metabolic Approach for the Management of Alzheimer's Disease Risk}

\author{
Vincenza Frisardi ${ }^{\mathrm{a}, \mathrm{b}, *}$ and Bruno P. Imbimbo ${ }^{\mathrm{c}}$ \\ ${ }^{a}$ Department of Neurological and Psychiatric Sciences, University of Bari, Bari, Italy \\ ${ }^{\mathrm{b}}$ Geriatric Unit and Gerontology-Geriatrics Research Laboratory, Department of Medical Sciences, \\ IRCCS “Casa Sollievo della Sofferenza”, San Giovanni Rotondo, Foggia, Italy \\ ${ }^{\mathrm{c}}$ Research and Development Department, Chiesi Farmaceutici, Parma, Italy
}

\section{INTRODUCTION}

Alzheimer's disease (AD) is the most frequent form of dementia in the elderly [1]. On the basis of future forecast, $\mathrm{AD}$ will have a tremendous impact on society and medical systems because dementia is the most important contributor to disability in the elderly [2]. The prevalence and incidence of dementia are relatively low in patients 60 to 65 years of age, but there is an exponential increase with age reaching almost $50 \%$ in those 85 years of age [3, 4]. After 90 years of age, the incidence of $\mathrm{AD}$ raises from $12.7 \%$ per year in the 90- to 94 -year-old age group, to $21.2 \%$ per year in the 95- to 99 -year-old age group, and to $40.7 \%$ per year in those at least 100 years old [5]. The progressive nature of $\mathrm{AD}$, leading to severe functional and cognitive deterioration and increased comorbid disease, is one of the major determinants of institutionalization and mortality in the elderly $[6,7]$. Consequently, the magnitude of this devastating disease has a significant impact on caregivers and healthcare systems.

\footnotetext{
*Correspondence to: Vincenza Frisardi, MD, PhD, Geriatric Unit and Gerontology-Geriatric Research Laboratory, IRCCS Casa Sollievo della Sofferenza, Viale Cappuccini 1, 71013, San Giovanni Rotondo, Foggia, Italy. E-mail: vfrisardi@yahoo.com.
}

At present, no effective treatments are available for prevention or cure of this devastating disease. Therefore, a growing burden of epidemiological data focused on risk factors [8]. Age and apolipoprotein $\mathrm{E} \varepsilon 4$ genotype are the most known $\mathrm{AD}$ risk factors [9], but they are not modifiable. Other possible risk factors for AD include female gender, ethnicity, family history of Down syndrome [9], maternal history of $\mathrm{AD}$ [10], education level (or cognitive reserve) [11], head trauma [12], and cerebrovascular risk factors [13]. Recently, great attention has been paid to the metabolic syndrome (MetS) [14] as a potential trigger of pathological molecular pathways dementia-linked. A strong and increasing body of evidence supports the association of MetS and metabolic determinants with cognitive impairment and dementia. In particular, MetS appeared to increase the risk for age-related cognitive decline, while for mild cognitive impairment (MCI) and its progression to dementia, the findings were too limited to draw any conclusion. Furthermore, the cumulative evidence did not suggest an association between MetS and the risk of developing overall dementia. On the contrary, several studies suggested that MetS may be linked to the risk of vascular dementia, while contrasting findings show a possible role of MetS in developing AD [14]. Moreover, 
it has been shown that MetS is also a risk factor for neurological disorders such as stroke and depression, as well as for dementia and AD [15]. Although molecular mechanisms underlying the mirror relationship between MetS and neurological disorders are not fully understood, it is becoming increasingly evident that all cellular and biochemical alterations observed in MetS (impairment of endothelial cell function, abnormality in essential fatty acid metabolism, and alterations in lipid mediators along with abnormal insulin/leptin signaling) may represent a pathological bridge between MetS and various neurological disorders.

The prevalence of obesity and MetS has increased over the past several decades and is expected to increase [16]. MetS is defined as a cluster of vascular and metabolic risk factors like visceral obesity, hypertension, dyslipidemia, and altered glycemic homeostasis [14]. Furthermore, it is characterized by an inflammatory cascade and release of several cytokines which act in several organs and systems, including the brain $[17,18]$. These changes modulate immune response and inflammatory reaction that lead to alterations in the hypothalamic "bodyweight/appetite/satiety" set point, following the initiation and development of MetS. This condition is the result of a change in lifestyle of the affluent society, and MetS could be prevented by a particular attention and diffusion of a protective diet model in association with a personalized physical activity plan.

Besides the vascular features of MetS influencing $\mathrm{AD}$ onset, the most intriguing aspect not explored yet is the metabolic-hormonal alterations over the course of MetS that may be detrimental for neuronal cells. In fact, metabolism depends on the feedback between central neuronal structures and peripheral organs [19]. One of the aims of this Supplemental Issue was to recognize possible pathological mechanisms underlying the suggested epidemiological link between MetS and AD. Therefore, the relationships between each component of MetS and AD have been examined in depth, as well as an attempt to obtain a comprehensive outlook over the simple addition of single MetS components. Starting from the hypothesis that insulin-resistance (from which result all metabolic disturbances of MetS) could be involved in the neuropathological cascade of AD, we postulated the existence of a "metabolic-cognitive syndrome" (MCS) [20]. This term is not a clinical label but rather a pathophysiological model where we can now identify patients with MetS plus cognitive impairment of degenerative or vascular origin, helping us to better understand neuropsychological and neuropathological features of these predemen- tia or dementia syndromes associated to MetS. The identification of a clinical profile of the MCS could be central in detecting in these patients a molecular profile of higher risk to develop predementia or dementia syndromes.

Another interesting aspect of this Supplemental Issue is the initial attempt to draw a common genetic background of both the pathological conditions, with the hope to stimulate further studies on this topic $[21,22]$. A variety of strategies have been used to identify genes influencing AD onset. Until recently, most reports came from linkage analysis and from studies that have examined the association of singlenucleotide polymorphisms. Thanks to the completion of the Human Genome Project, the development of public databases and advances in high-throughput, high-density genotyping technology, our knowledge is increased. Indeed, genome-wide association studies have emerged as an increasingly effective tool for identifying genetic contributions to complex diseases and represent the next frontier for furthering our understanding of the underlying etiologic, biological, and pathologic mechanisms associated with chronic complex disorders [23].

However, many issues are still unsolved. First of all, there is the doubt as to whether amyloid- $\beta(A \beta)$ and hyperphosphorylated tau protein are causal in neurodegenerative damage or are the tip of the iceberg of other underlying mechanisms of neurodegeneration. Moreover, these neuropathological hallmarks of $\mathrm{AD}$ may represent even a cellular attempt of response to any kind of neuronal insult (e.g., vascular, ischemic, or oxidative). If the latter hypothesis were true, drugs targeting $A \beta$ could be detrimental for $\mathrm{AD}$ patients. In fact, in the last 15 years, most of the efforts of the pharmaceutical industry in $\mathrm{AD}$ have been directed against the production and accumulation of $A \beta$ [24]. Unfortunately, these efforts have not produced, up to now, effective therapies, given that the exact mechanisms leading to $\mathrm{AD}$ are largely unknown, thereby limiting the identification of effective disease-modifying therapies. Converging evidence from both genetic at-risk cohorts and clinically normal older individuals suggests that the pathophysiological process of AD begins years, if not decades, before the diagnosis of clinical dementia [25]. Probably, it is mandatory to start earlier with a potential AD treatment in order to counteract the disease progression. The recent introduction of new diagnostic criteria of $\mathrm{AD}$ based on specific cognitive patterns and reliable biomarkers [26] may open a new paradigm of therapeutic intervention based on the distinction of two preclinical states of $\mathrm{AD}$ in 
which individuals are free of cognitive symptoms. One group is formed of 'asymptomatic subjects at risk for AD' with biomarker evidence of AD pathology. The other group is formed of 'presymptomatic AD subjects' carrying genetic determinants, which eventually will develop the disease [27]. New drugs should be tested in these two populations of 'asymptomatic' or 'presymptomatic' subjects rather than in AD patients. Very recently, the National Institute on Aging and the Alzheimer's Association charged a workgroup with the task of revising the 1984 criteria for AD dementia [28], developing criteria for the symptomatic predementia phase of $\mathrm{AD}$ (MCI due to $\mathrm{AD}$ ) [29] and defining the preclinical stages of $\mathrm{AD}$ for research purposes and toward earlier intervention at a stage of AD when some disease-modifying therapies may be most efficacious. New and promising drugs are still under investigation, but at this time, according to the latest discoveries, it is necessary to synthesize new and old concepts, looking at this disease in a more comprehensive manner. In this way, a more accurate clinical selection of subjects at high-risk to develop $\mathrm{AD}$ who would successfully benefit from these upcoming treatments would be possible. In fact, selecting patients only on the basis of well-known risk factors seems to be inadequate in light of new knowledge. Therefore, as tumor markers are useful for follow-up rather than diagnosis, similarly, we believe that screening of subjects for plasma or cerebrospinal fluid biomarkers would not be sufficient for an early diagnosis of AD. Given that the onset of this disease is probably the result of interaction among genetic and environmental factors, we are aware that the research agenda should consider new platforms of study, going beyond the monolithic outlook of $\mathrm{AD}$, with the synthesis of epidemiological, experimental, and biological data, under a unique pathophysiological model as a point of reference for further advances in the field.

\section{REFERENCES}

[1] Wimo A, Prince M (2010) World Alzheimer Report. Alzheimer's Disease International, London, pp. 1-12.

[2] Comas-Herrera A, Wittenberg R, Pickard L, Knapp M (2007) Cognitive impairment in older people: Future demand for long-term care services and the associated costs. Int J Geriatr Psychiatry 22, 1037-1045.

[3] Ferri CP, Prince M, Brayne C, Brodaty H, Fratiglioni L, Ganguli M, Hall K, Hasegawa K, Hendrie H, Huang Y, Jorm A, Mathers C, Menezes PR, Rimmer E, Scazufca M, Alzheimer's Disease International (2005) Global prevalence of dementia: A Delphi consensus study. Lancet 366, 2112-2117.

[4] Jorm AF, Jolley D (1998) The incidence of dementia: A metaanalysis. Neurology 51, 728-733.
[5] Corrada MM, Brookmeyer R, Paganini-Hill A, Berlau D, Kawas CH (2010) Dementia incidence continues to increase with age in the oldest old: The 90 study. Ann Neurol 67, 114-121.

[6] Sousa RM, Ferri CP, Acosta D, Albanese E, Guerra M, Huang Y, Jacob KS, Jotheeswaran AT, Rodriguez JJ, Pichardo GR, Rodriguez MC, Salas A, Sosa AL, Williams J, Zuniga T, Prince M (2009) Contribution of chronic diseases to disability in elderly people in countries with low and middle incomes: A 10/66 Dementia Research Group population based survey. Lancet 374, 1821-1830.

[7] Eaker ED, Vierkant RA, Mickel SF (2002) Predictors of nursing home admission and/or death in incident Alzheimer's disease and other dementia cases compared to controls: A population-based study. J Clin Epidemiol 55, 462-468.

[8] Matthews FE, Brayne C, Lowe J, McKeith I, Wharton SB, Ince P (2009) Epidemiological pathology of dementia: Attributable-risks at death in the Medical Research Council Cognitive Function and Ageing Study. PLoS Med 6, e1000180.

[9] Duara R, Barker WW, Lopez-Alberola R, Loewenstein DA, Grau LB, Gilchrist D, Sevush S, St George-Hyslop S (1996) Alzheimer's disease: Interaction of apolipoprotein E genotype, family history of dementia, gender, education, ethnicity, and age of onset. Neurology 46, 1575-1579.

[10] Farrer LA, O’Sullivan DM, Cupples AC, Growdon JH, Myers RH (1989) Assessment of genetic risk for Alzheimer's disease among first-degree relatives. Ann Neurol 25, 485-493.

[11] Stern Y, Gurland B, Tatemichi TK, Tang MX, Wilder D, Mayeux R (1994) Influence of education and occupation on the incidence of Alzheimer's disease. JAMA 271, 10041010 .

[12] Mortimer JA, van Duijn CM, Chandra V, Fratiglioni L, Graves AB, Heyman A, Jorm AF, Kokmen E, Kondo K, Rocca WA, Shalat SL, Soininen H, Hofman A, for the Eurodem Risk Factors Research Group (1991) Head trauma as a risk factor for Alzheimer's disease: A collaborative re-analysis of case control studies. EURODEM Risk Factors Research Group. Int $J$ Epidemiol 20, S28-S35.

[13] Kuller LH, Lopez OL, Newman A, Beauchamp NJ, Burke G, Dulberg C, Fitzpatrick A, Fried L, Haan MN (2003) Risk factors for dementia in the cardiovascular health cognition study. Neuroepidemiology 22, 13-22.

[14] Panza F, Solfrizzi V, Logroscino G, Maggi S, Santamato A, Seripa D, Pilotto A (2012) Current epidemiological approaches to the metabolic-cognitive syndrome. $J$ Alzheimers Dis 30, 31-75.

[15] Farooqui AA, Farooqui T, Panza F, Frisardi V (2012) Metabolic syndrome as a risk factor for neurological disorders. Cell Mol Life Sci 69, 741-762.

[16] Elias MF, Goodell AL, Waldstein SR (2011) Obesity, cognitive functioning and dementia: Back to the future. $J$ Alzheimers Dis 30, 113-125.

[17] Gustafson D (2012) Adiposity and cognitive decline: Underlying mechanisms. J Alzheimers Dis 30, 97-112.

[18] de la Monte SM (2012) Triangulated mal-signaling in Alzheimer's disease: Roles of neurotoxic ceramides, ER stress, and insulin resistance reviewed. J Alzheimers Dis 30, 231-249.

[19] Wiedmer P, Chaudhary N, Rath M, Yi CX, Ananthakrishnan G, Nogueiras R, Wirth EK, Kirchner H, Schweizer U, Jonas W, Veyrat-Durebex C, Rohner-Jeanrenaud F, Schürmann A, Joost HG, Tschöp MH, Perez-Tilve D (2012) The HPA axis modulates the CNS melanocortin control of liver triacylglyceride metabolism. Physiol Behav 105, 791-799. 
[20] Frisardi V, Solfrizzi V, Capurso C, Imbimbo BP, Vendemiale G, Seripa D, Pilotto A, Panza F (2010) Is insulin resistant brain state a central feature of the metabolic-cognitive syndrome? J Alzheimers Dis 21, 57-63.

[21] Lahiri DK, Maloney B (2012) The "LEARn" (latent early-life associated regulation) model: An epigenetic pathway linking metabolic and cognitive disorders. J Alzheimers Dis 30, 1530.

[22] Reitz C (2011) Dyslipidemia and dementia: Current epidemiology, genetic evidence, and mechanisms behind the associations. J Alzheimers Dis, doi: 10.3233/JAD-2011110599.

[23] Guerreiro RJ, Hardy J (2011) Alzheimer's disease genetics: Lessons to improve disease modelling. Biochem Soc Trans 39, 910-916.

[24] Frisardi V, Solfrizzi V, Imbimbo PB, Capurso C, D'Introno A, Colacicco AM, Vendemiale G, Seripa D, Pilotto A, Capurso A, Panza F (2010) Towards disease-modifying treatment of Alzheimer's disease: Drugs targeting beta-amyloid. Curr Alzheimer Res 7, 40-55.

[25] Morris JC (2005) Early-stage and preclinical Alzheimer disease. Alzheimer Dis Assoc Disord 19, 163-165

[26] Dubois B, Feldman HH, Jacova C, Dekosky ST, BarbergerGateau P, Cummings J, Delacourte A, Galasko D, Gauthier S, Jicha G, Meguro K, O’Brien J, Pasquier F, Robert P, Rossor M, Salloway S, Stern Y, Visser PJ, Scheltens P (2007) Research criteria for the diagnosis of Alzheimer's disease: Revising the NINCDS-ADRDA criteria. Lancet Neurol 6, 734-746.
[27] McKhann GM, Knopman DS, Chertkow H, Hyman BT, Jack CR Jr, Kawas CH, Klunk WE, Koroshetz WJ, Manly JJ, Mayeux R, Mohs RC, Morris JC, Rossor MN, Scheltens $\mathrm{P}$, Carrillo MC, Thies B, Weintraub S, Phelps $\mathrm{CH}$ (2011) The diagnosis of dementia due to Alzheimer's disease: Recommendations from the National Institute on Aging-Alzheimer's Association workgroups on diagnostic guidelines for Alzheimer's disease. Alzheimers Dement 7, 263-269.

[28] Albert MS, DeKosky ST, Dickson D, Dubois B, Feldman HH, Fox NC, Gamst A, Holtzman DM, Jagust WJ, Petersen RC, Snyder PJ, Carrillo MC, Thies B, Phelps CH (2011) The diagnosis of mild cognitive impairment due to Alzheimer's disease: Recommendations from the National Institute on Aging-Alzheimer's Association workgroups on diagnostic guidelines for Alzheimer's disease. Alzheimers Dement $\mathbf{7}$ 270-279.

[29] Sperling RA, Aisen PS, Beckett LA, Bennett DA, Craft S, Fagan AM, Iwatsubo T, Jack CR Jr, Kaye J, Montine TJ, Park DC, Reiman EM, Rowe CC, Siemers E, Stern Y, Yaffe K, Carrillo MC, Thies B, Morrison-Bogorad M, Wagster MV, Phelps CH (2011) Toward defining the preclinical stages of Alzheimer's disease: Recommendations from the National Institute on Aging-Alzheimer's Association workgroups on diagnostic guidelines for Alzheimer's disease. Alzheimers Dement 7, 280-292. 